\title{
Long-term Personal Relationships and Well-being
}

\author{
Richard B. Gunderman, MD, MPH, $\mathrm{PhD}^{\mathrm{a}}$
}

Danielle A. Bly, BS ${ }^{\mathrm{b}}$

a. Department of Radiology, Indiana University School of Medicine, 702 North Barnhill Drive, Room 1053, Indianapolis, IN 46202

b. Indiana University School of Medicine, Indianapolis, IN 46202

Key Words: Burnout; Relationships; Marriage; Well-being; Physician well-being

The well-being of physicians is the product of at least two distinct domains of life: the professional and the personal. Most recent study of physician well-being and its counterpart, burnout, tends to focus on the professional side. But the personal domain often plays at least as large a role in overall well-being, and for many physicians, the single most significant aspect of personal life is their most important long-term relationship, often marriage. A flourishing relationship offers companionship and promotes both physical and emotional well-being, while a failing one can take an equally substantial toll. Those seeking to enhance physician well-being need to understand the features of thriving relationships. Two important sources of insight on such relationships are empirical research and imaginative literature.

\section{Empirical Research}

Empirical research offers one approach to understanding why some relationships thrive while others do not. For example, in 1999 a researcher at Washington University, John Gottman, published The Seven Principles for Making Marriage Work. His seven principles are: enhancing love maps, nurturing fondness

This is the author's manuscript of the article published in final edited form as:

Gunderman, R. B., \& Bly, D. A. (2018). Long-term Personal Relationships and Well-being. Academic Radiology, 25(11), 1510-1512. https://doi.org/10.1016/j.acra.2018.06.003 
and admiration, turning toward each other instead of away, allowing partners to exert influence, solving solvable problems, overcoming gridlock, and creating shared meaning (1). Other researchers have developed different frameworks for understanding long-term relationships, one of which emphasizes the importance of mutual support (2). The fact that such theories tend to overlap substantially makes Gottman's model a reasonable one to focus on.

By "love map" Gottman refers to partners' understandings of each other, which could include their biography, their hopes and fears, and their general outlook on life. When partners better understand one another's love maps, he argues, they are better positioned to communicate and connect with each other. For example, if one partner wants to express appreciation for what the other has done, situating it in the context of the other's love map will enhance the degree to which they both understand and benefit from it. Conversely, failing to understand a partner's inner life and experience of the world will make effective communication less likely.

Partners who nurture fondness and admiration take time to reflect on each other's noble qualities, in effect reminding themselves of the roots of their love. One such approach is to ponder a particular quality, such as honesty or compassion, that makes the partner admirable. Another is to reflect on past incidents or shared experiences that serve as reminders of the partner's best qualities. To do the opposite - to focus on qualities or past experiences that lead to resentment against a partner-is to sow the seeds of discord. Implicit in both approaches is the idea that what partners habitually attend to will, over time, powerfully shape their level of fulfillment in their relationship.

Turning toward the partner means seeking out opportunities for companionship and connection. One recent study showed that physicians' marital satisfaction is associated with the number of waking minutes they spend with their partners (3). When partners fail to spend quality time with each other, think about each other little when apart, or fail to share the events and experiences that make up their lives, the probability increases that they will grow apart. Simply put, it is important that each partner develop the habit of shifting attention when the other makes a bid for it. Such bids may take very different forms, 
from sharing a hurtful incident to recounting a humorous story, but in each case, the key is to engage rather than to disengage. Underlying this advice is the notion that neglect can prove no less harmful than outright hostility.

Allowing partners to exert influence means that neither partner conceptualizes the relationship as made up of two parties, a sculptor and clay. Where one partner assumes the role of shaper, expecting to do all the shaping while undergoing none of it, the long-term prospects for the relationship are poor. More recent work also supports this notion that a need to be in control can wreak havoc on a relationship (4). It is far more realistic and fruitful for both partners to expect to be shaped by each other, and that such influence will, at least in large part, help them to become better people. Implicit here is the notion that neither partner enters into the relationship as the fully developed person they are meant to be, and the relationship itself plays an important role in completing this growth and maturation.

When Gottman suggests solving solvable problems, he points at least tacitly to the fact that some problems are likely to prove insoluble. As we have seen, it is both unrealistic and counterproductive to approach a long-term relationship as an opportunity to recreate the partner as a different person. He is also suggesting that no one is perfect, and one feature of a thriving relationship is the effort to accept the partner's faults. Having said this, however, it is also important to recognize when problems admit of a solution, and to look for opportunities to solve them, an effort that will often involve at least a degree of compromise. To achieve mutual understanding, each spouse must resist the impulse to escalate conflict.

Gridlock refers to a condition in which neither partner will budge, and continued focus on a conflict only makes each feel worse. While many techniques are available to get out of gridlock, such as looking for an opportunity to find humor or express affection in it, the key is less a matter of technique than always looking for a way to transcend it. In many cases, the key is to seek out the underlying issues responsible for it. For example, one partner may perceive another's request to do or change something as an attack. If partners can reexamine such situations and recognize that no attack is intended, gridlock can often be overcome. 
Finally, partners need to work together to creature shared meaning. Often attached to a spiritual dimension in marriage, the inner lives of partners need to overlap and even intertwine to a substantial extent if the relationship is to thrive. Ultimately, long-term relationships are less about completing certain tasks, such as maintaining a household or raising a family, than about sharing experience in such a way that it means much the same thing to each partner. A long-term relationship is not so much a contract, in which each party gets what he or she wants from the other, as a community of spirit, in which each really knows and cherishes their life partner.

\section{Literature}

Another resource for understanding relationships and their role in a rich and full human life is imaginative literature. Where empirical research generally assumes that we can learn what we need to know from studying the lives of many ordinary people, literature offers the opportunity to see how a single remarkable person - the author-regards these same matters. Of course, the value of such insights will depend on the degree to which the author is a truly observant, understanding, and even wise human being. In some cases, however, we enjoy the opportunity to explore the insights of the greatest authors in world literature, which offer great promise in enhancing our understanding of marriage.

Consider, for example, perhaps the greatest novel ever composed, Leo Tolstoy's Anna Karenina. Composed in the 1870s, the book begins with one of the best-known lines in world literature: "Every happy family is alike, but each unhappy family is unhappy in its own way". With this opening, Tolstoy announces the great theme of the novel — the traits that happy relationships share in common, and the ways in which unhappy ones differ from one another. As relationships get better and better, he is saying, they tend to become more alike one another, implying that good relationships all share similar priorities and habits.

Anna Karenina interweaves the stories of several couples. Stiva and Dolly have a large family, in which Dolly finds great meaning, yet to which Stiva, a philanderer, believes he cannot be expected to confine 
himself. Anna is a brilliant, self-absorbed woman who finds her honorable yet dry husband Karenin unsatisfying and seeks romance with a dashing cavalry officer, Vronsky, who has no concept of true family life. Kitty, Dolly's younger sister, falls at first for Vronsky, but later learns to appreciate the charms of a thoughtful and idealistic landowner, Levin, whose overtures she at first spurned. Through the stories of these characters, Tolstoy provides a depth of psychological insight unknown to empirical research.

Consider, for example, the character of Stiva, an affable man who is liked by all, yet who again and again makes choices on the spur of the moment without reference to any larger and more permanent context of meaning save his sense that life should satisfy him. When he cheats on his wife, he does so sincerely believing that no reasonable person could begrudge him such satisfaction, yet when he seeks reconciliation with his wife, he genuinely professes his love and desire to keep himself solely to her. Stiva is not exactly a bad person, but he does not reliably situate his life in any larger context of meaning, and in private moments believes that his only mission in life is to enjoy himself.

Beyond such rich psychological insights, Tolstoy offers deep insights on the meaning of relationships. For example, he implies that every particular relationship is but a particular instance of a much larger and preexisting reality that will long survive the dissolution of any union, whether through divorce, disregard, or death. From Tolstoy's point of view, when a couple marries, they are becoming part of a reality that has larger purposes, and which functions far more to mold the partners than serve as a device for their personal satisfaction. It is through committed relationships, Tolstoy might say, that we enjoy one of our best opportunities to become fully who we are meant to be.

How can this be? In essence, we come into the world thinking almost entirely only of ourselves. A baby, for example, wants everything for itself. Over time, however, we can learn to care about others, not just as means for our own satisfaction, but for their own sakes. We learn that we are not solitary individuals but parts of larger wholes, such as relationships and families. And it is only through our service to such larger wholes that we learn to care about other people, thereby becoming the caring human beings we are meant 
to be. Those who live for self alone lead not only solitary but impoverished existences. We become fully ourselves only by sharing our best with others.

Consider Anna. She thinks not about her husband or her child, but about the romantic love for which she longs. To her the work of marriage has become tiresome and unfulfilling. She wants to be desired in a new way, and she supposes that if only she had a more exciting partner, his desire would infuse her life with more excitement. She fails to realize that in all of this she is thinking primarily, and often only, of herself. Over the course of the novel, she becomes more and more curved in on herself, to the point that it drives her mad when her lover pays attention to anything other than her. Meanwhile, her son and daughter languish unattended, and she sinks more and more deeply into despair.

Part of the problem in such relationships is a failure of presence. And the culprit is not merely the amount of time one of the spouses — often the physician — spends at work. The real problem is a failure of commitment to the spouse, born out of a delusion that life in different circumstances would be more exhilarating. People fall into the trap of assuming that they are more important than they are, and that they deserve better, and that all they have to do to find true happiness is to correct their mistake and find their true love. In fact, Tolstoy suggests, the real challenge is to find the meaning and fulfillment offered in everyday family life.

This represents a radically different view of relationships than the one chronicled in the tabloids and glossy magazines of our own day. The purpose of relationships is not for each of us to show how important we are by attracting a beautiful, rich, famous, or powerful mate. The real purpose of a life-long relationship is to develop our capacity to love. We assay the quality of a relationship not by what one partner has been able to extract from the other but by the degree to which each has learned to find fulfillment in giving his or her best to the other. In short, we make a relationship not by what we get but by what we give. 
If Tolstoy is right about this, then long-term relationships have much to offer physicians, not only as a refuge from a demanding life at the office, but as an opportunity to develop and hone some of the human excellences on which a truly fulfilling career in medicine depends. For example, taking good care of patients requires that we genuinely care for them, and long-term relationships represent an opportunity for deeper understanding of what it means to care. Likewise, a good relationship requires loyalty, an enduring commitment to the welfare of another person, which represents a capacity that needs to be developed by good physicians, as well. An opportunity for liberation opens up when we focus our whole presence on a single person.

\section{Conclusion}

Empirical research and literature share an assumption about marriage and its role in a well-being —an assumption that many great physicians have shared about medicine. It is simply this: if we wish to make the most of a personal or professional life calling, we must strive continuously to understand it more deeply. Long-term relationships and medicine both ask a lot of a person, but rightly understood, both also offer rich rewards. Above all, empirical research and imaginative literature highlight two enduring truths: (1) it is in sharing what we have with others that we most develop what we have to share and (2) that it is not so much in getting but ultimately through giving that we stand the best chance of finding a fulfilling life. 


\section{References}

1. Gottman JM, Silver N. The seven principles for making marriage work. 1st ed. New York, NY: Crown Publishers, 1999.

2. Perlman RL, Ross PT, Lypson ML. Understanding the medical marriage: physicians and their partners share strategies for success. Acad Med 2015; 90:63-68.

3. Shanafelt TD, Boone SL, Dyrbye LN, et al. The medical marriage: a national survey of the spouses/partners of US physicians. Mayo Clin Proc 2013; 88:216-225.

4. Meyers MF. Medical marriages and other intimate relationships. MJA 2004; 181:392-394. 